\title{
Evaluation of Government service quality from perspective of reliability
}

\author{
Abdulla Jaafar Desmal', \\ Mohd Khalit Bin Othman'2, \\ Suraya Binti Hamid ${ }^{3}$ \\ Faculty of Computer Science and Information \\ Technology University of Malaya, Kuala Lumpur, Malaysia \\ 1a.desmal@outlook.com, \\ 2mkhalit@um.edu.my, \\ ${ }^{3}$ suraya_hamid@um.edu.my \\ Ali Hussain Zolait \\ College of Information Technology \\ University of Bahrain \\ Sakheer, Kingdom of Bahrain \\ azolait@uob.edu.bh
}

\begin{abstract}
Measuring online service quality is critical for organizations. Due to the lack of exhaustive service quality framework for mobile government services, it creates difficulties for the service providers to evaluate the service delivered to end-users. Mobile government services is a unique online service portal that needs a compatible quality framework that is constructed with consideration of each of the particular features of mobility. Therefore, the present study aims to analyses a single service quality dimension of mobile government which is "reliability". Using a systematic literature review, the authors were able to find the relevant attributes belonging to the service quality dimension of "reliability" and compatible with the unique features of mGovernment service portal. The finding are five attributes which are timeliness, accuracy, error-free, service promise, and confidentiality.
\end{abstract}

Keywords: reliability, system reliability, mobile government, online service quality, e-service quality, mobile services.

\section{INTRODUCTION}

The power of ICTs with internet connections lies in its universality [1;2]. It is a necessity and a strategic issue that online services are enabling users with limited knowledge to access and use such services with fewer efforts and more flexibility [3; 4]. The Internet has proven to be a powerful tool that helps to reduce the digital divide [5]. This is due to its broad potential audience, low independence invisible regulators, linguistic impositions of content [6]. Hence, this encourages organizations to launch services to be available for the audience through mobile devices. Services at mobile platforms were developed with extended use of technology in many sectors such as health, finance, insurance, education [7]. Government sectors employed smart techniques to governmental launch services at mobile devices, which is called Mobile Government Services (mGovernment) [8]. The main goal of mGovernment is to enable public perform services with less time and less efforts from anywhere and at any time [9]. Government sectors get benefits from such services by an increase of the efficiency and quality of services provided and by saving the environment. Therefore, continued use of such services creates efficient way for services provider and service receiver. Measuring of service quality at mGovernment portal guided to understand expectations of public toward service provided and enable for more development of service strategies.

Due to the weakness of service quality framework in the context of mobile government services, it creates difficulties for government sectors to evaluate the services and to understand users' 
expectations $[10 ; 11]$. When using different service quality framework (such as e-service, e-commerce, e-business) in the mGovernment environment, it creates inaccurate results. This is because each of the services has its features and according to uniqueness, the services quality framework is constructed. Therefore, few of the previous studies on mGovernment services [10; 12] have recommended constructing a comprehensive framework that can evaluate mGovernment services with consideration of mobility features.

Reliability is one of significant service quality dimensions at online services portal $[2 ; 13]$, which evaluates the provided services based on users' perspective in term of accuracy and consistency [14]. Evaluation of service reliability is associated with system operation [15]. It an essential element at service quality measurement since it aims to evaluate the software functions at the perspective of end users $[16 ; 17]$. It's a technique that allows to understand the usage of a software [18], in terms of accuracy, the status of errors, the context of the provided services to meet the user's expectations $[19 ; 21]$. Therefore, this study is focused on the evaluation of mGovernment services based on the quality attributes of reliability.

\section{LITERATURE REVIEW}

To get insight of reliability attributes of mGovernment service quality, it's necessary to study the relevant concepts that are associated with the environment of the mGovernment portal.

\section{A. Mobile Government service}

It's a technique of using smart technologies supported with wireless internet connections to provide governmental services through mobile applications [8; 11]. The main goal of mobile government services is to keep the public closed to government sector through performing services at mGovernment portal [22]. In the mGovernment context, the service provider is the government sector, while the citizens or public is the user/service receiver [23]. The strategy of mGovernment is to ensure accessibility and availability of government services and information at any time and anywhere. It has unique features that differs from the electronic government such as mobility, portability, and personalization [24]. It enables users to perform transaction through handled devices $[25 ; 26]$. Some of the most famous services of the mGovernment portal are in the sectors of health, education, finance, banking, and insurance [10;27]. Popularity of mobile devices among people has encouraged government sectors to launch mGovernment application to cover the services at government sectors [28]. Flexibility, efficiency, and performance are associated with successful applications created at mGovernment portal [27]. Hence, the user is the success factor and the applications characteristics and features have to reflect the expectations of the public to provide an interactive environment.

\section{B. Electronic service quality}

With extensions of online services, there has been a focus on service quality by researchers and practitioners to enable the organization or the service provider to evaluate the services based on users' satisfaction. Services quality is the comparison of expectations and perceptions of the services delivered to users [2]. Quality of service creates competition among service providers (organizations), which leads to providing the services to end-users with the best values [29]. It draws the relationship between service providers and clients [30], and between the perception and delivery of services [31]. Studies of [32;33] stated that the evaluation of the quality of the services should be more specific in terms of service environment, dimensions, and attributes. Because the quality of service rises the business rank and reputation, efforts of organizations were put to measure the quality and understand the user's expectations to improve the operations functions [20]. In term of offline services, the most popular service quality measurement is proposed by [34] which is called SERVQUAL, is constructed of ten dimensions, and the updated version of the same model reduced to five dimensions only that are "tangibles, reliable, responsiveness, assurance, and empathy". 
However, at e-service quality environment, the author [15] proposed an e-service quality model called E-S-QUAL consisting of four main dimensions "efficiency, fulfillment, system availability, and privacy". The e-service quality model of "eTailQ" proposed by [35] consisting of four main dimensions "website quality, privacy/security, customer service, and reliability/fulfillment". Extensions of e-services encourages researchers to proposed compatible service quality models to fit with the features of each environment. In this case, e-government service quality has been studied, such as the study of [36] proposed a model consisting of eight main dimensions "system quality, information quality, service quality, dispositional trust, institutional trust, interpersonal trust, continues intention, and EWOM intention". Study of [16] proposed e-government service quality model constructed of four main dimensions "responsiveness, security, efficiency, and reliability".

With differences of e-service quality models, the common goal of measuring the services is to evaluate the delivery process of services and understand users' expectations. Conducting such evaluation enhances satisfaction of users and encourages organizations to provide competitive services.

\section{Reliability's evaluation at online service quality}

Reliability is an attribute that measures the degree to which a product operates without failures under conductions established for a certain period of time [16;19]. Reliability is a quantitative attribute that has been widely analyzed at the scope of software engineering [37;38]. The concept of software reliability means that a particular software is performing the functions without errors. These errors can be related to software design, implementation, programming, or any other technical issues [39; 40]. However, in the field of online service quality, one of the main dimensions used to evaluate the service quality from users' prospective is measuring the reliability. Study of [41] aimed to develop and validate a service quality model for services provided through mobile devices in the health sector. Study of [41] measured the reliability of system as an attribute that belongs to dimension of platform quality, which analyses the reliability based on three technical features of smoothly, reliably, and dependable.

\section{TABLE I. DEFINITIONS OF RELIABILITY AT ONLINE SERVICE}

\begin{tabular}{|c|c|}
\hline Reference & Definition \\
\hline [41] & "Indicates the degree to which the platform is dependable over time". \\
\hline$[42]$ & $\begin{array}{l}\text { "The ability of the mobile bank to perform the promised customer service dependably } \\
\text { and accurately". }\end{array}$ \\
\hline$[18]$ & \multirow{2}{*}{ "It is a strong predictor for overall quality and customer satisfaction". } \\
\hline$[35]$ & \\
\hline$[43]$ & "The extent to which the provider keeps its service promise". \\
\hline$[44]$ & "The capacity to play out the guaranteed benefit constantly and precisely". \\
\hline$[45]$ & \multirow{2}{*}{ "The ability to perform the promised service dependably and accurately". } \\
\hline$[20]$ & \\
\hline$[46]$ & "The extent to which the system runs correctly when individuals are using it". \\
\hline$[15]$ & $\begin{array}{l}\text { "It is the correct technical functioning of the site and the accuracy of service promises } \\
\text { (having items in stock, delivering what is ordered, delivering when promised), billing, and } \\
\text { product information". }\end{array}$ \\
\hline
\end{tabular}




\section{I. QUALITY}

The concept of reliability as a service quality has been defined by previous studies as stated in Table I. The authors [42] aimed to identify the main service quality dimensions that can be used to evaluate mobile banking. Using the technique of critical incident, the authors proposed (17) key dimensions and the "reliability" was the one of the fundamental constructs proposed in the quality model. It used to evaluate the reliability of mobile service quality based on three attributes of "correct service, service promise as advertised, and keeping the provided services promise". The study stated that the reliability measures the silence factors in online service quality which can be detected through users' evaluation of such services.

The authors [18] argue that the measurement scale of e-service quality is constructed according to "goal-oriented" attitudes without considering hedonic criteria within service quality framework. According to this problem, the authors proposed a service quality framework consisting of both criteria of goal-oriented and hedonic attributes. Hence, the service quality model of "eTransQual" proposed as a transaction follow-up steps to evaluate the service quality based on five dimensions which are as follows:

"functionality/design, enjoyment, process, reliability, and responsiveness". The dimension of reliability designed to evaluate the online services according to the attributes of timeliness, accuracy, product availability, breadth and depth of product range, encoding of personal information, and confidentiality.

The study of [35] stated that the concept of quality is associated with satisfactions of customers, which enhanced their loyalty, trust, and continues use of the services. In this case, the organizations pay more attention to develop the strategies of quality evaluation with the aim of reaching business targets. Using online survey and focus group, the study of [35] constructed a service quality model called "eTailQ" consisting of four dimensions of "website design, fulfillment/reliability, privacy/security, and customer service". The dimension of reliability evaluates the attributes of service quality based on its reliably and desirable using (15) questions within the category of reliability. Evaluation of service reliability enhances the functionality of online services and improves the flexibility of interaction with users.

The study of [44] uses the Structural Equation Model to investigate the service quality dimensions that have impact on the customer satisfaction of mobile banking in Bangladesh. Data was collected using the questionnaire with a total of (240) respondents. The study found that the five dimensions of the service quality named "tangibility, reliability, responsiveness, assurance, and empathy" have influence on the satisfaction of users at mobile banking service quality. The dimension of reliability constructed with the attributes of "error free and problem solving".

Based on previous literature, the main issues were to relate the concept of reliability to be compatible with the online environment, to enable users evaluate the services with attributes that are understandable by users and helpful for service providers to identify the functions that need to be revised and developed.

\section{RESEARCH METHODOLOGY}

The authors use the review of literature to investigate the concept of reliability from the perspective of service quality at online platforms. The present study follows the literature review steps of [47] that are constructed of four essential steps which are planning, selection, extraction, and execution of theories. A total of four main electronic libraries were used during the current research which were "ACM, Web of Science, Scopus, and SAGE". The researchers didn't specify a particular research period due to lack of research in the area of measuring the electronic services based on reliability. The keywords that were use dare "mobile government", "electronic government", "electronic services", "e-service quality", "online service quality", and "reliability". Using these keywords along with Bolean operators "AND" with "OR", the researchers extracted the studies that can support the area of the present study. 
The summary of steps performed in the systematic literature review are illustrated in Figure I. The first step of research is planning, that enables researchers to state the main goal of the present study. Selection, was the next step which enables to identify the research articles that add knowledge to the area of study. Abstracts reviewing, was the next step to take a look into abstracts, introduction, and the conclusions for selected studies. Execution, which aims to extract the attributes of reliability at e-service quality. Final step is to tabulate the collected data for further analysis.

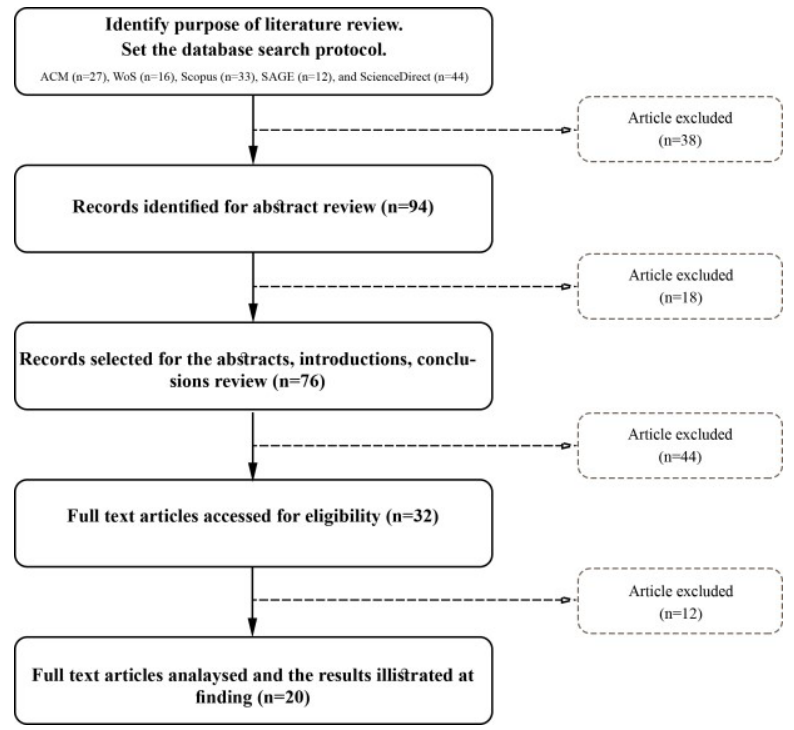

Fig. 1. Systematic literature review uses at the present study

\section{PROPOSED SERVICE QUALITY MODEL TO EVALUATE}

THE RELIABILITY OF M-GOVERNMENT SERVICES

Based on previous studies, the extracted attributes of reliability can guide to construction of a model to evaluate the service quality at mobile government based on reliability. Due to the lack of studies at the previous mentioned scope, the researchers use the attributes of reliabilities from various online service quality framework such as e-commerce, e-services, mGovernment, and e-government. Hence, based on matrix table, the researchers categorized the most attributes uses among previous researchers to evaluate the quality of reliability. This section lists the most important attributes based on previous literature.

\section{A. Timeliness}

The attribute of timeliness reliability gets the most frequency among other attributes. It refers to providing the services to users on-time due to its direct impact on users' satisfactions [48; 49]. At the portal of m-Government, the timeliness illustrated at delivering of governmental services to end users on-time [7]. When users are getting the services without lateness, it encourages them to deal with $\mathrm{m}$-Government in the future due to positive past experience [10]. The first factor of formulating user's satisfaction is receiving the required services on-time. In this case, there are many techniques that let user know the status of the transaction with estimation time period that can be taken to get the service done, by inform users through email, SMS, or online tracking of 
the status of a service. Previous studies have included the timeliness as an attribute to evaluate the reliability of e-services such as $[15 ; 18 ; 20 ; 35 ; 45 ; 46]$.

\section{B. Accuracy}

The attribute of accuracy refers to the degree of concordance between the result of measurement and true value of the measured [50]. The service is accurate when its status is closer to the true value. Reliability evaluation of mobile government services is based on accuracy depending on the status of the availability of cost per services, clearly identifying the types/categories of each service, availability of services on mGovernment platform, and any other costs of providing a service [51]. Accuracy keeps services clear for public which has an effect on customer satisfaction. Previous studies in the area of electronic services have included the efficiency within the dimension of reliability to evaluate the electronic services $[15 ; 18 ; 20 ; 35]$.

\section{Error-free}

Electronic services have been developed with the prospect of technical or programming errors that may face by end users [39; 40]. The service provider has to ensure that the status of the online platform is free of errors at programming or any other technical issues that disrupt the functional process. Some of the most common errors in online services platforms are the syntax, runtime and logical. Other studies $[20 ; 35 ; 44 ; 45]$ have included the attributes of "error-free" within the quality dimension of reliability.

\section{Service promise}

The service promise is a formal statement that expresses the corporate commitment to the organization's customers in terms of service items and the level of inventory service to offer in each of them [52-54]. At mobile government services, the government service provider promises that the delivered services are going to be as per users' needs [55-57]. The statement of service promise is related to the policy and strategic planning of service providers. This enhances the trust toward such service from public. Due to the importance of measuring the "service promise", previous studies have included it as part of reliability dimension $[15 ; 35 ; 42]$.

\section{E. Confidentiality}

This refers to the availability status of security and privacy. Mobile government services are delivered through mobile devices and it requires more security and privacy when comparing to services based on desktop computer [31; 58], [59]. Transactions performed by users at mGovernment include financial and personal information. The study of [7] argues that it is necessary to conduct regular updates of security and privacy procedures especially when it comes to services based on mobile application. Previous studies such as $[18 ; 41 ; 42 ; 45 ; 46]$ have measured the reliability quality with consideration of confidentiality's attribute.

\section{F. Measuring the reliability at m-Government}

Based on previous studies (see details at appendix A), the most frequent attributes that can be used to evaluate the reliability of online services platforms are timeliness, accuracy, error-free, service promise, and confidentiality. Therefore, the present study proposes a model that can be used in the context of m-government services to evaluate the delivered services based on the quality of reliability. 


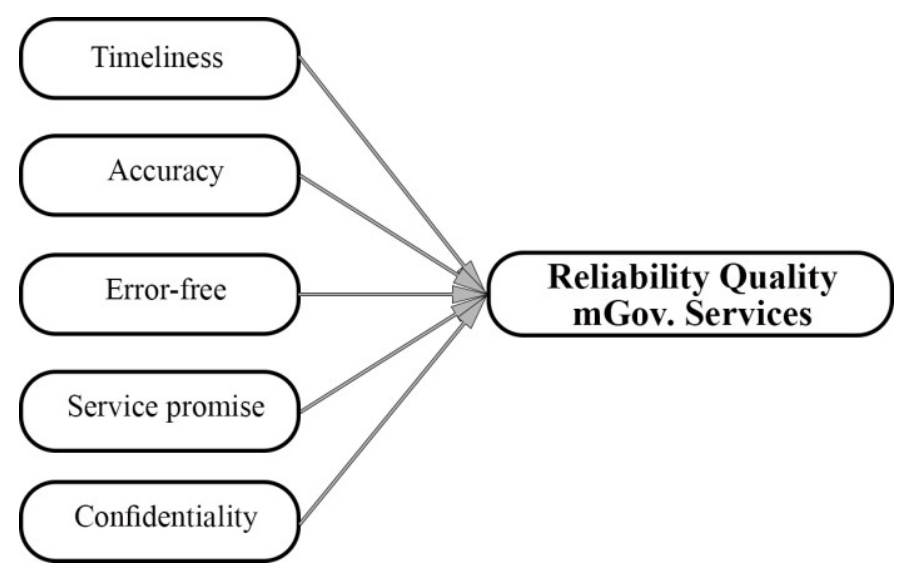

Fig. 2: Proposed model for reliability quality evaluation at mGovernment service

\section{RESEARCH IMPLICATION}

The proposed model improves the evaluation system of mGovernment service quality by expanding the concept of reliability with more attractive attributes. It adds value to the measurement scales of electronic service platforms particularly of mGovernment services. Understanding users' expectations of service quality is a fundamental role of service provider through applying the evaluation process with a compatible scale that fits to the service context. Therefore, the proposed attributes of reliability can be used by researchers for further analysis in terms of qualitative or quantitative studies. The present research is limited to the environment of mobile government services and the proposed attributes are analysed with consideration of mGovernment in the form of Government To Citizens - G2C. Future research is required to conduct more analysis for other services categories provided by government sector through mobile devices.

\section{CONCLUSIONS}

Mobile government services are expanding to meet the user's requirements. Meeting the public requirements of such services requires to conduct an evaluation using an applicable and compatible measurement scale that fits with the environment and features of mGovernment portal. Therefore, the present study is picking one of the fundamental quality dimensions which is "reliability" which can be used to evaluate the services provided through mGovernment in terms of their reliability. The researcher uses the systematic literature review to extract the relevant attributes of reliability ofonline service quality. A total of (14) different attributes have been listed to find the frequency from previous studies. The findings show that there are (5) significant attributes that can be used to evaluate the reliability quality of services delivered through mGovernment portal.

\section{REFERENCES}

[1]. Cui J., Zhou H., Xu Y. et al. OOABKS: Online/offline attribute-based encryption for keyword search in mobile cloud, Inf. Sci. (Ny). 2019, vol. 489, pp. 63-77.

[2]. Rahi S., Abd.Ghani M., HafazNgah A. Integration of unified theory of acceptance and use of technology in internet banking adoption setting: Evidence from Pakistan, Technol. Soc, 2019, pp. 101-120.

[3]. Bindu N., Sankar C.P., Kumar K. S. From conventional governance to e-democracy: Tracing the evolution of e-governance research trends using network analysis tools, Gov. Inf. Q., 2019, vol. 36, no. 3, pp. 385-399. 
[4]. Barth S., de Jong M.D. T., Junger M. et al. Putting the privacy paradox to the test: Online privacy and security behaviors among users with technical knowledge, privacy awareness, and financial resources, Telemat. Informatics, 2019, vol. 41, pp. 55-69.

[5]. Akram M.S., Malik A., Shareef M.A. et al. Exploring the interrelationships between technological predictors and behavioral mediators in online tax filing: The moderating role of perceived risk, Gov. Inf. Q., 2019, vol. 36, no. 2, pp. 237-251.

[6]. Sharma S.K., Sharma M. Examining the role of trust and quality dimensions in the actual usage of mobile banking services: An empirical investigation, Int. J. Inf. Manag., 2019, vol. 44, pp. 65-75.

[7]. Johansson D., Lassinantti J., Wiberg M. Mobile e-services and open data in e-government processes, in Proceedings of the 17th International Conference on Information Integration and Web-based Applications \&Services - iiWAS '15, 2015, pp. 1-10.

[8]. Jaafar N.A. K.A., Othman M.K., Hamid S. et al. Exploring the interaction's quality attributes of Mobile Government services, Journal of Physics: Conference Series, 2019, vol. 1339.

[9]. Almarashdeh I., Alsmadi M.K. How to make them use it? Citizens acceptance of M-government, Appl. Comput. Informatics, 2017, vol. 13, no. 2, pp. 194-199.

[10]. Al-Hubaishi H.S., Ahmad S.Z., Hussain M. Exploring mobile government from the service quality perspective, J. Enterp. Inf. Manag. 2017, vol. 30, no. 1, pp. 4-16.

[11]. Chanana L., Agrawal R., Punia D.K., Service Quality Parameters for Mobile Government Services in India, Glob. Bus. Rev., 2016, vol. 17, no. 1, pp. 136-146.

[12]. Shareef M.A., Dwivedi Y.K., Stamati T. et al. SQ mGov: A Comprehensive Service-Quality Paradigm for Mobile Government, Inf. Syst. Manag., 2014, vol. 31, no. 2, pp. 126-142.

[13]. Tam C., Oliveira T. Understanding the impact of m-banking on individual performance: DeLone\& McLean and TTF perspective, Comput. HumanBehav., 2016, vol. 61, pp. 233-244.

[14]. Santos J. E-service quality: a model of virtual service quality dimensions, Manag. Serv. Qual. AnInt. J., 2003, vol. 13, no. 3, pp. 233-246.

[15]. Parasuraman A., Zeithaml V.A., Malhotra A., E-S-QUAL a multiple-item scale for assessing electronic service quality, J. Serv. Res., 2005, vol. 7, no. 3, pp. 213-233.

[16]. Sharma S.K., Govindaluri S. M., Gattoufi S. Understanding and predicting the quality determinants of e-government services, J. Model. Manag., 2015, vol. 10, no. 3, pp. 325-340.

[17]. Janda S., Trocchia P.J., Gwinner K.P. Consumer perceptions of Internet retail service quality, Int. J. Serv. Ind. Manag., 2002, vol. 13, no. 5, pp. 412-431.

[18]. Bauer H.H., Falk T., Hammerschmidt M. eTransQual: A transaction process-based approach for capturing service quality in online shopping, J. Bus. Res., 2006, vol. 59, no 7, pp. 866-875.

[19]. Sharma S.K. Adoption of e-government services, Transform. Gov. People, Process Policy, 2015, vol. 9, no. 2, pp. 207-222.

[20]. Huang E.Y., Lin S.-W., Fan Y.-C. M-S-QUAL: Mobile service quality measurement, Electron. Commer. Res. Appl., 2015, vol. 14, no. 2, pp. 126-142.

[21]. Amritesh C., Misra S., Chatterjee J. Conceptualizing egovernment service quality under credence based settings, Int.J. Qual. Reliab. Manag., 2014, vol. 31, no. 7, pp. 764-787.

[22]. Liu Y., Li H., Kostakos V. et al. An empirical investigation of mobile government adoption in rural China: A case study in Zhejiang province," Gov. Inf. Q., 2014, vol. 31 , no. 3 , pp. $432-442$.

[23]. Al-Huan O. Toward the Utilization of M-Government Services in Developing Countries: a Qualitative Investigation, Int.J. Bus. Soc. Sci., 2012, vol. 3, no. 5, pp. 155-160.

[24]. Mandari H.E., Chong Y.-L., Wye C.-K. The influence of government support and awareness on rural farmers' intention to adopt mobile government services in Tanzania, J. Syst. Inf. Technol., 2017, vol. 19, no. 1/2, pp. 42-64.

[25]. Saxena S. Role of 'perceived risks' in adopting mobile government (m-government) services in India, Foresight, 2018, vol. 20, no. 2, pp. 190-205. 
[26]. Reddick C.G., Zheng Y. Determinants of citizens' mobile apps future use in Chinese local governments, Transform. Gov. People, ProcessPolicy, 2017, vol. 11, no. 2, pp. 213-235.

[27]. Sharma S.K., Al-Badi A., Rana N.P. et al. Mobile applications in government services (mGApp) from user's perspectives: A predictive modelling approach," Gov. Inf. Q., 2018, vol. 35, no. 4, pp. 557-568.

[28]. Eom S.-J.J., Kim J.H. The adoption of public smartphone applications in Korea: Empirical analysis on maturity level and influential factors," Gov. Inf. Q., 2014, vol. 31, no. suppl. 1, pp. S26-S36.

[29]. Chi T. Understanding Chinese consumer adoption of apparel mobile commerce: An extended TAM approach, J. Retail. Consum. Serv., 2018, vol. 44, pp. 274-284.

[30]. Wang Y.S., Tseng T.H., Wang W.T. et al. Developing and validating a mobile catering app success model, Int. J. Hosp. Manag., 2019, vol. 77, pp. 19-30.

[31]. Theodosiou M., Katsikea E., Samiee S. et al. A Comparison of Formative Versus Reflective Approaches for the Measurement of Electronic Service Quality, J. Interact. Mark., 2019, vol. 47, pp. 53-67.

[32]. Santa R., MacDonald J. B., Ferrer M. The role of trust in eGovernment effectiveness, operational effectiveness and user satisfaction: Lessons from Saudi Arabia in e-G2B, Gov. Inf. Q., 2019, vol. 36, no. 1, pp. 39-50.

[33]. Blut M.E-Service Quality: Development of a Hierarchical Model, J. Retail., 2016, vol. 92, pp. 500-517.

[34]. Parasuraman A., Zeithaml V.A., Berry L.L. SERQUAL: A Multiple-Item scale for Measuring Consumer Perceptions of Service Quality, J. Retail., 1988, vol. 64, pp. 12-40.

[35]. Wolfinbarger M., Gilly M.C. eTailQ: Dimensionalizing, measuring and predicting etail quality, J. Retail., 2003, vol. 79, no. 3, pp. 183-198.

[36]. Nulhusna R., Sandhyaduhita P. I., Hidayanto A. N. et al. The relation of e-government quality on public trust and its impact on public participation, Transform. Gov. People, ProcessPolicy, 2017, vol. 11, no. 3, pp. 393-418.

[37]. Santouridis I., Trivellas P., Tsimonis G. Using E-S-QUAL to measure internet service quality of e-commerce web sites in Greece, Int.J. Qual. Serv. Sci., 2012, vol. 4, no. 1, pp. 86-98.

[38]. Ghosh M., Measuring electronic service quality in India using E-SQUAL, Int. J. Qual. Reliab. Manag., 2018, vol. 35, no. 2, pp. 430-445.

[39]. McMillin B. Software Engineering, Computer, 2018.

[40]. Finkbine R.B. Metrics and Models in Software Quality Engineering, ACM SIGSOFT Softw. Eng. Notes, 2004.

[41]. Akter S., D'Ambra J., Ray P., Service quality of mHealth platforms: development and validation of a hierarchical model using PLS, Electron. Mark., 2010, vol. 20, no. 3-4, pp. 209-227.

[42]. Jun M., Palacios S. Examining the key dimensions of mobile banking service quality: an exploratory study, Int. J. Bank Mark., 2016, vol. 34, no. 3, pp. 307-326.

[43]. Fassnacht M., Koese I. Quality of Electronic Services: conceptualizing and testing a hierarchical model, J. Serv. Res., 2006, vol. 9, no. 1, pp. 19-37.

[44]. Khan A.G., Lima R.P., Mahmud M.S. Understanding the Service Quality and Customer Satisfaction of Mobile Banking in Bangladesh: Using a Structural Equation Model, Global Business Review, 2018, Sep. 23, p. 097215091879555.

[45]. Kim K.-H., Kim K.-J., Lee D.-H. et al. Identification of critical quality dimensions for continuance intention in mHealth services: Case study of onecare service, Int. J. Inf. Manage., 2019, vol. 46, pp. 187-197.

[46]. Du J., Lu J., Wu D., Li H. et al. User acceptance of software as a service: Evidence from customers of China's leading e-commerce company, Alibaba, J. Syst. Softw., 2013, vol. 86, no. 8, pp. 2034-2044.

[47]. Okoli C. A guide to conducting a standalone systematic literature review, Commun. Assoc. Inf. Syst., 2015, vol. 37. 
[48]. Suryn W., Software Quality Engineering: A Practitioner's Approach. Hoboken: Wiley-IEEE Press, 2014.

[49]. Carroll J.M., Rosson M.B. Usability engineering, in Computing Handbook: Information Systems and Information Technology. Boca Raton, 2014.

[50]. Jun M., Palacios S. Examining the key dimensions of mobile banking service quality: an exploratory study, Int.J. Bank Mark., 2016, vol. 34, no. 3, pp. 307-326.

[51]. Ghosh S., Surjadjaja H., Antony J. Optimisation of the determinants of e-service operations, Bus. Process Manag. J., 2004, vol. 10, no. 6, pp. 616-635.

[52]. Resende M., Cardoso V. Mapping service quality in electricity distribution: An exploratory study of Brazil, Util. Policy, 2019, vol. 56, pp. 41-52.

[53]. Tuzkaya G., Sennaroglu B., Kalender Z.T. et al. Hospital service quality evaluation with IVIF-PROMETHEE and a case study, Socioecon. Plann. Sci., 2019, vol. 68.

[54]. Prentice C., Wang X., Loureiro S.M. C. The influence of brand experience and service quality on customer engagement, J. Retail. Consum. Serv., 2019, vol. 50, pp. 50-59.

[55]. Rahi S., Abd.Ghani M. Investigating the role of UTAUT and eservice quality in internet banking adoption setting, TQM J., 2019, vol. 31, no. 3, pp. 491-506.

[56]. Shayestehfar R., Yazdani B. Bank service quality, TQM J., 2019, vol. 31, no. 1, pp. 28-51.

[57]. Zuo W., Zhu W., Chen S. et al. Service quality management of online car-hailing based on PCN in the sharing economy, Electron. Commer. Res. Appl., 2019, vol. 34, p. 100827.

[58]. Hsu T.-H., Tang J.-W. Development of hierarchical structure and analytical model of key factors for mobile app stickiness, J. Innov. Knowl., 2020, vol. 5, no. 1, pp. 68-79.

[59]. Oriade A., Schofield P. An examination of the role of service quality and perceived value in visitor attraction experience, J. Destin. Mark. Manag., 2019, vol. 11, pp. 1-9.

\section{APPENDICES}

\section{Appendix A: Matrix table of reliability's attributes at mGovernment service quality}

\begin{tabular}{|c|c|c|c|c|c|c|c|c|c|c|c|c|c|c|c|c|}
\hline \multirow[b]{2}{*}{ 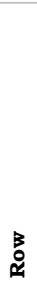 } & \multirow[b]{2}{*}{ 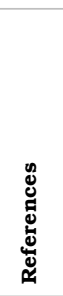 } & \multirow[b]{2}{*}{ 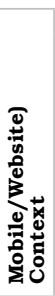 } & \multicolumn{14}{|c|}{ Attributes of reliability service quality } \\
\hline & & & 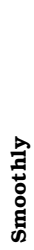 & 党 & 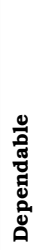 & 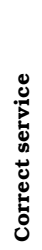 & 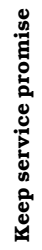 & 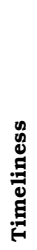 & 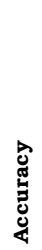 & 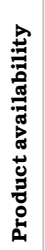 & 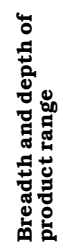 & 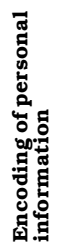 & 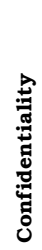 & 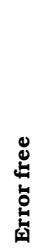 & 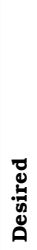 & 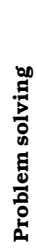 \\
\hline 1 & {$[41]$} & $\mathrm{M}$ & $\checkmark$ & $\checkmark$ & $\checkmark$ & & & & & & & & $\checkmark$ & & & \\
\hline 2 & {$[42]$} & M & & & & $\checkmark$ & $\checkmark$ & & & & & & $\checkmark$ & & & \\
\hline 3 & {$[18]$} & $\mathrm{W}$ & & & & & & $\checkmark$ & $\checkmark$ & $\checkmark$ & $\checkmark$ & $\checkmark$ & $\checkmark$ & & & \\
\hline 4 & [35] & $\mathrm{W}$ & & & & $\checkmark$ & $\checkmark$ & $\checkmark$ & $\checkmark$ & $\checkmark$ & & & & $\checkmark$ & & \\
\hline 5 & [43] & $\mathrm{W}$ & & $\checkmark$ & & & & & & & & & & & $\checkmark$ & \\
\hline 6 & [44] & M & & & & & & & & & & & & $\checkmark$ & & $\checkmark$ \\
\hline 7 & {$[45]$} & M & & & & & & $\checkmark$ & & & & & $\checkmark$ & $\checkmark$ & & \\
\hline 8 & {$[20]$} & M & & & $\checkmark$ & & & $\checkmark$ & $\checkmark$ & & & & & $\checkmark$ & & $\checkmark$ \\
\hline 9 & {$[46]$} & $\mathrm{W}$ & & & & & & $\checkmark$ & & & & & $\checkmark$ & & & \\
\hline 10 & [15] & $\mathrm{w}$ & & & & & $\checkmark$ & $\checkmark$ & $\checkmark$ & & & & & & & \\
\hline \multicolumn{2}{|c|}{ Frequency } & & 1 & 2 & 2 & 2 & 3 & 6 & 4 & 2 & 1 & 1 & 5 & 4 & 1 & 2 \\
\hline
\end{tabular}

